\title{
Coração de Estudante: relato de experiência de um grupo voltado à educação em um Centro de Atenção Psicossocial II
}

\author{
Luna Cassel Trott* \\ Daniela Ribeiro Schneider**
}

\section{Resumo}

As práticas de cuidado na Rede de Atenção Psicossocial são desafios diários dos profissionais dos serviços de saúde mental em busca de desconstruir formas hegemônicas de cuidado, antes centradas no modelo manicomial e suas práticas de exclusão social. A articulação entre saúde mental e educação é uma importante ação para pensar a inclusão social dos usuários, já que muitos, na multideterminação do sofrimento psíquico, também viveram processos de exclusão escolar. O artigo é um relato de experiência de caráter pedagógico e terapêutico, realizada em um CAPS II. A oficina "Coração de Estudante" teve encontros semanais com o intuito de ser espaço de reflexão acerca das experiências do campo educacional e incentivar os usuários do serviço em seu ingresso à Educação de Jovens e Adultos e de ampliação das possibilidades de ser e de retomada de projetos de vida.

Palavras-chave: Saúde Mental. Exclusão Escolar. Educação de Jovens e Adultos. Reforma Psiquiátrica. Atenção Psicossocial.

\section{Student Heart: experience report of an education group in a Psychosocial Care Center}

\section{Abstract}

Care practices in the Psychosocial Care Network are daily challenges for mental health professionals to deconstruct hegemonic forms of care, previously centered on the asylum model and its practices of social exclusion. The articulation between mental health and education is an important ac-

* Universidade Federal do Rio Grande do Sul. lunatrott@gmail.com

** Universidade Federal de Santa Catarina. danischneiderpsi@gmail.com 
tion to think about the social inclusion of users, since many, in the multidetermination of psychological distress, also lived processes of school exclusion. The article is a report of pedagogical and therapeutic experience, carried out in a CAPS II. The workshop "Heart of Student" had weekly meetings to be a space for reflection on the experiences in the educational field and encourage users in their entry into Youth and Adult Education and to expand the possibilities of being and life projects.

Keywords: Mental Health. School Exclusion. Youth and Adult Education. Psychiatric Reform. Psychosocial Attention.

\section{Corazón del Estudiante: informe de experiencia de un grupo Educativo en un Centro de Atención Psicosocial}

\section{Resumen}

Las prácticas de atención en la Red de Atención Psicosocial son desafíos diarios para que los profesionales de la salud mental deconstruyan formas hegemónicas de atención, previamente centradas en el modelo de hospitalización psiquiátrica y sus prácticas de exclusión social. La articulación entre la salud mental y la educación es una acción importante para pensar en la inclusión social de los usuarios, ya que muchos, en la multideterminación del sufrimiento psíquico, también vivieron procesos de exclusión escolar. El artículo es un informe de experiencia pedagógica y terapéutica, realizado en un CAPS II. El taller "Corazón del estudiante" tuvo reuniones semanales para ser un espacio de reflexión sobre las experiencias en el campo educativo y alentar a los usuarios a ingresar a la Educación de Jóvenes y Adultos y para ampliar las posibilidades de ser y reanudar proyectos de vida.

Palabras clave: Salud mental. Exclusión escolar. Educación de jóvenes y adultos. Reforma psiquiátrica. Atención psicosocial.

\section{"Nova aurora a cada dia"1 - no caminho da refor- ma psiquiátrica}

O tensionamento entrelógicas de cuidado e atenção psicossocial é objeto de muitas discussões em nossos dias. Com a mudan-

1 Os nomes dados aos subtítulos do artigo são em alusão aos versos da música "Coração de Estudante", de Milton Nascimento. A música dá nome ao grupo realizado em um CAPS II, cujas experiências serão relatadas neste artigo. 
ça de rumos no Governo Federal, desde 2016, as políticas de Saúde Mental vêm, paulatinamente, sendo modificadas, sendo chancelada a mudança definitiva em 2019, já sob os auspícios do Governo Bolsonaro, com uma retomada na ênfase das internações hospitalares e em métodos biológicos de tratamento, como a eletroconvulsoterapia, eixos centrais da velha lógica manicomial (DELGADO, 2019). Além disso, o congelamento dos investimentos em saúde, educação, assistência social, entre outras áreas, por meio da PEC 095, vai pauperizando as políticas públicas e a atenção à população.

As diferentes opiniões a respeito do tratamento de uma pessoa em sofrimento psíquico que surgem entre os familiares, por exemplo, que só veem na internação a alternativa de cuidado, em certa medida, são reflexo de como esses tensionamentos estão dados no próprio saber profissional e acadêmico. Esse tensionamento é real, atual e podemos dizer que só é possível por efeito do movimento histórico da chamada Reforma Psiquiátrica. Trata-se de um movimento que teve origem em vários países europeus, mas que a Itália foi seu expoente máximo, influenciando outros países no mundo com diferentes direcionamentos de cuidado e reinserção social, ao denunciar as violências praticadas nos manicômios e direcionar o fechamento desse tipo de dispositivo, abrindo formas de cuidado, alternativas, realizando a crítica epistemológica ao saber médico dominante da psiquiatria (AMARANTE, 1996). Esse movimento teve grande influência no Brasil, que, num processo histórico, caracterizado, principalmente, pela luta de profissionais da área de saúde mental e familiares, institucionalizou um regulamento que dispõe sobre "a proteção e os direitos das pessoas portadoras de transtornos mentais e redireciona o modelo assistencial em saúde mental" (BRASIL, 2001), a partir da lógica antimanicomial (AMARANTE, 1996). A regulamentação de 2001 prevê um serviço de saúde aberto e comunitário que intensifique os cuidados relacionados à saúde mental e que possibilite a reinserção social desses sujeitos (BRASIL, 2004).

A partir dessa regulamentação surgem os Centros de Atenção Psicossocial (CAPS), como uma alternativa do Sistema público 
de Saúde brasileiro (SUS) ao modelo de internação em hospitais psiquiátricos, caracterizados por suas condições precárias, pela ruptura dos vínculos sociais da maioria dos pacientes, pela violação dos direitos humanos dos usuários (ARBEX, 2013). Até os anos 1990, essas instituições eram a única escolha de tratamento para pessoas em situação de sofrimento mental grave (BRASIL, 2004).

É importante entender que a lógica manicomial está, para além do espaço do manicômio, na própria supressão da individualidade, no controle dos comportamentos, na ausência da lógica de direitos (BOCCARDI, 2015). Nesse sentido, lembramos da inquietação já colocada: o tensionamento das lógicas de cuidado sobre a saúde mental é um fato. Por isso, é necessário compartilhar da experiência de Basaglia (1996), quando este diz:

O Manicômio está ainda presente: todavia faltam serviços e estruturas adequadas; a qualidade de intervenção é muitas vezes decadente e insuficiente, muitos familiares denunciam o fato de ter que arcar, muitas vezes sem auxílio ou com pouco apoio, com o peso do parente doente. Mas ninguém quer mais o manicômio (p. 11).

Contraditoriamente, o manicômio passa a ser retomado dentro da nova política de saúde mental no Brasil, aprovada em 2019 (BRASIL, 2019). Diante disso, entendemos que a Luta Antimanicomial está ainda em curso, apesar de sua institucionalização pelos anos de consolidação da Reforma Psiquiátrica Brasileira. Isso fala sobre o grande desafio que os profissionais da área possuem em inventar e reinventar cotidianamente suas práticas na tentativa de desconstruir formas comuns e hegemônicas do cuidado. Isto é, trabalhar na criação de formas de atenção aos sujeitos, que busquem garantir a autonomia e a cidadania dos usuários, conforme prerrogativas do modo psicossocial (COSTA-ROSA; LUZIO; YASUI, 2003).

Diante dessas novas formas de reinventar o cuidado e pensar a reinserção social dos usuários na lógica antimanicomial, este trabalho apresenta uma proposta de intervenção, desenvolvida em um CAPS II de uma cidade de Santa Catarina, como possibilidade de 
pensar essa intervenção como uma ação de educação em saúde na rede de atenção psicossocial. A educação em saúde está relacionada à lógica da promoção da saúde, e trata de processos que abrangem a participação dos usuários no contexto de sua vida cotidiana, nas reflexões acerca de seus processos históricos e condições de saúde e seus condicionantes, visando construir sua autonomia (MACHADO et al., 2007). A experiência faz parte de um período de estágio profissionalizante na área de "Saúde e processos clínicos", na formação em Psicologia, realizada em 2017. Trata-se de um projeto de reabilitação social em uma área muitas vezes preterida no cuidado a usuários da saúde mental - os processos educativos.

Consideramos que essa proposta contribua para a criação dessas novas possibilidades de atenção e cidadania, ao considerar a integração social dos sujeitos usuários aos processos cotidianos de vida, sendo esta uma das partes fundamentais dessa lógica de cuidado. Isto é, como parte do tratamento, deve-se pensar em inclusão e reabilitação psicossocial, orientação para as comunidades na busca de conviver com as diferenças, a oposição à opção de segregação e à contraposição ao controle dos comportamentos (BOCCARDI, 2015).

Quando se fala de pessoas com sofrimento psíquico grave, busca-se adotar um referencial clínico que busque indicadores para o sofrimento para além da sintomatologia, compreendendo essa situação como um "modo de estar no mundo, fenômeno existencial humano - de cunho interno, relacional e dinâmico" (COSTA, BRAGA, 2013, p. 548). Esse olhar busca dar conta da integralidade do sujeito, ainda que cientes de que esse tipo de sofrimento implica a própria desconstrução de formas comuns e hegemônicas de viver e de estar na cidade. Ou seja, faz-se necessário lidar com o que é desviante, incomum e diferente, diante de modos dominantes de existências na contemporaneidade. Entre esses modos está a condição de acesso aos conhecimentos e a trajetória educativa das pessoas que, quando em processo de sofrimento, perdem muitas vezes a oportunidade de acompanhar os processos educacionais re- 
gulares, sofrendo, muitas vezes, de mais um processo de exclusão entre tantos que condicionam a loucura. Assim, esses mistérios do que fazer psicossocial está para além da criação de equipamentos e dispositivos, mas na forma de criar modos de viver, pensar e agir que afirmem a potência da vida, que revelem os mecanismos de controle e cronicidade na base do sofrimento ou que produzam rupturas com o paradigma manicomial (DIMENSTEIN, 2006).

O objetivo deste artigo é relatar essa experiência educativa desenvolvida em um CAPS II e promover reflexões sobre seus efeitos para o cuidado integral de pessoas com sofrimento psíquico grave.

\section{"Pode estar aqui do lado" - a construção de prá- ticas inclusivas}

Dimenstein (2006) aponta para possíveis estratégias de intervenções nos CAPS voltadas para a reinserção social de portadores de transtornos mentais, na busca de autonomia e garantia de direitos desses cidadãos. Coloca as estratégias também como forma de se opor ao risco da criação de uma nova cronicidade, que muitas vezes se expressa na retenção de usuários nos serviços de saúde substitutivos, em gestões resistentes à expansão para outros setores de cuidados e à construção de portas de saída desses serviços.

Algumas dessas estratégias são a expansão da articulação com a rede básica de cuidado, tendo o CAPS como articulador dessa rede em saúde mental; ter os serviços residenciais terapêuticos (SRT's) como possibilidade de criar uma vida na cidade e circulação livre nos espaços públicos; a capacitação de Acompanhantes Terapêuticos como dispositivo de inserção extramanicomial, circulação pela cidade e estratégia de enlace social; consolidação da Política Nacional de Humanização e a implementação do Apoio Matricial; a construção de uma rede integrada de atenção à saúde; a capacitação de profissionais, entre outros (DIMENSTEIN, 2006).

As formas de exclusão vivenciadas por sujeitos em sofrimento psíquico grave são diversas: no âmbito da circulação na cidade, do acesso à cultura, do próprio acesso a serviços de saúde e assistência, 
na discriminação social eles carregam, no acesso à educação e nos mais diversos direitos que lhes deveriam estar garantidos, mas que, muitas vezes, lhes são negados. Algumas práticas no interior dos CAPS buscam a reinserção de usuários com foco na superação dessas exclusões, como grupos terapêuticos, grupos de socialização, grupos que pensem a reinserção no mercado de trabalho, práticas de economia solidária, assembleia de usuários, grupo de associação dos usuários, entre outros.

Entretanto, apesar de haver algumas experiências em CAPS brasileiros, pouca atenção é dada para a questão do acesso e da garantia à educação a esses sujeitos. Essa forma de exclusão, vivenciada por muitos dos usuários dos CAPS, está comumente relacionada ao abandono do ensino regular desde muito cedo em suas vidas.

Não existem informações precisas no Brasil sobre alfabetização e escolarização de usuários dos serviços de saúde mental, contudo, a presença nesses serviços permite indicar que o número de usuários não alfabetizados ou que possuem uma baixa escolarização parece maior que na população em geral (VASCONCELOS, 2014).

$\mathrm{O}$ abandono escolar normalmente está relacionado às próprias condições sociais de permanência na escola, mas também se explica pelo estigma do sofrimento psíquico que exclui o sujeito socialmente e, por conseguinte, o segrega do ambiente escolar (AZEVEDO et al., 2014). Esse abandono, muitas vezes, aparece travestido, ainda na trajetória de estudos na infância, como fracasso escolar, o que permite uma desresponsabilização do Estado pela criação e manutenção das condições para a permanência. Tal situação demonstra a inadequação que ocorre em grande parte das escolas em sua função de oferecer ensino para populações desprivilegiadas (CAMARGO, 2015). Por sua vez, a questão da saúde mental, em intersecção com a evasão escolar na infância, escracha como a condição dos sujeitos portadores de transtornos mentais está relacionada à questão social.

A questão social está no tocante da expressão das desigualdades da sociedade capitalista, onde a produção torna-se coletiva, 
mas a apropriação dos frutos continua privada e monopolizada por uma pequena parte da sociedade (IAMAMOTO, 1999, citado por LUSTOSA e ROSA, 2017). Assim, essa questão se reflete nas pessoas com sofrimentos mentais, por meio da exclusão da produção social, já que são consideradas inaptas para o trabalho, e além do sofrimento, carregam ainda preconceito, estigmas, estereótipos e permanecem segregadas, o que tende a agravar o sofrimento psíquico e a excluí-las dos espaços de trabalho e educação.

As pessoas com sofrimento psíquico que abandonam os bancos escolares, por essa complexidade de motivos que são reconhecidos, podem acabar por sofrer as consequências da ausência dos conteúdos escolares, do acesso à sociabilidade e do sentido de ser social e comunitário, além do esvaziamento da formação crítica enquanto pertencente a um grupo social. Isto é, a ideia da incapacidade as segrega dos outros e, muitas vezes, o sujeito fica sem lugar (LUSTOSA E ROSA, 2017).

Diante disso, algumas experiências vêm sendo desenvolvidas no sentido de buscar autonomia dos sujeitos por meio da educação. Alguns CAPS, por exemplo, têm desenvolvido oficinas de alfabetização e implementando a Educação de Jovens e Adultos dentro dos serviços (AZEVEDO et al., 2014). Outros realizam o encaminhamento dos usuários para os EJAS (KANTORSKI et al., 2011), apontando como saídas importantes para a reinserção social dos usuários.

Essas experiências demonstram que a Educação de Jovens e Adultos para esse público promove a aquisição de conhecimentos básicos, mas também de habilidades socioculturais, o que é considerado o mais importante para as/os profissionais que acompanham essas atividades. Nesse sentido, a escola auxilia na construção da autonomia desses sujeitos, saindo do foco da atenção exclusiva ao transtorno e dando mais importância às novas relações possíveis nesses espaços. O usuário, dessa forma, é tomado como um sujeito de potencialidades e autonomia na construção de sua reinserção social (KANTORSKI et al., 2011). 
Por sua vez, levanta-se a necessidade de adaptação das formas de ensino à realidade desses sujeitos, já que não se trata somente de transferir conteúdos, mas incluí-los na dimensão da vida social. Nessa direção, evidencia-se a importante figura do professor e do vínculo formado entre este e o usuário, que se apresenta como fator fundamental na ampliação de habilidades e no sucesso da continuidade dos usuários no projeto de regresso aos estudos. Também se destaca a importância de o educador estar atento às individualidades dos alunos, seus ritmos em relação à aprendizagem e às diferentes formas de encarar o processo educacional (AZEVEDO et al., 2014).

Camargo (2015) levanta a questão de como a inclusão na EJA pode ser uma estratégia de promoção à saúde. A pesquisadora identifica fatores como a modificação das demandas familiares, a ocupação do tempo ocioso, a minimização dos efeitos da timidez, a aquisição de mais independência e autonomia para diversas atividades, como utilizar o transporte coletivo, ler cartas, administrar melhor as medicações, melhorar desempenho em atividades religiosas a partir da interpretação de textos, entre outros, como fatores importantes que desembocam na promoção da saúde.

\section{"Há que se cuidar do broto" - interlocuções entre saúde mental, educação e inclusão}

O que essas experiências trazem, ao fim e ao cabo, é a importância da criação de novas estratégias para a efetivação e a garantia de um direito básico: o direito à educação. Ora, se a Reforma Psiquiátrica veio contra os processos de exclusão, segregação e ausência de direitos em relação a pessoas em situação de sofrimento mental grave, fundamental para isso é a inclusão social desses sujeitos a partir da afirmação e da efetivação de seus direitos.

A Lei 10.216, do ano de 2001, foi fator fundamental nesse sentido, já que, apesar de já termos uma Constituição prevendo os direitos fundamentais dos cidadãos brasileiros (a Constituição de 1988), foi essa lei que reconheceu formalmente e versou especi- 
ficamente sobre os direitos das pessoas em sofrimento mental. O direito à educação, então, apesar de estar entre os direitos fundamentais, deve ser pensado no sentido da permanência das pessoas com sofrimento mental, já que o abandono escolar é recorrente devido às dificuldades e discriminação sofridas nesses espaços (CORREIA, 2011). A IV Conferência de Saúde Mental, de 2010, também colocou em pauta ações intersetoriais entre a educação e a rede de atenção psicossocial para aproximar esses setores e promover a inclusão das pessoas com deficiência e transtornos mentais nas escolas (VASCONCELOS, 2014).

Apesar do reconhecimento desse direito e da necessidade de aproximação desses campos, ainda não há uma compreensão mais abrangente sobre a questão da inclusão de pessoas com sofrimento mental nas instituições educativas. Nas legislações vigentes, importantes avanços foram conquistados na área educativa em relação a pessoas com deficiência, por exemplo. A Lei de Diretrizes Básicas da Educação (BRASIL, 1996) considera em um de seus capítulos a modalidade de "educação especial", oferecida para educandos com deficiência, transtornos globais do desenvolvimento, altas habilidades ou superdotação. O movimento político, cultural, social e pedagógico da inclusão, que repudia discriminações e, segundo o qual, todos têm o direito de conviver em dado ambiente em comum sem diferenciação, teve sua tese institucionalizada a partir da Declaração de Salamanca (1994), pela Convenção Interamericana da Guatemala (2001), pela Política Nacional de Educação Especial na Perspectiva da Educação Inclusiva (2008) e pelo Plano Nacional de Educação (2010) (ESTANISLAU e BRESSAN, 2014).

Entretanto, ainda falta entendimento sobre as legislações que façam referência à questão da saúde mental de forma mais ampla. A partir do debate da educação inclusiva, a educação especial deixa de ser voltada para pessoas com deficiência e passa a ser voltada a qualquer educando que demande uma atenção especial. Na oferta de Atendimento Educacional Especializado (AEE), alguns quadros são reconhecidos, como os de deficiência intelectual, física, visual, 
auditiva, transtornos globais do desenvolvimento, psicose infantil e altas habilidades ou superdotação. Entretanto, outros quadros que não apresentem comprometimento intelectual ainda carecem de apoio na legislação (ESTANISLAU e BRESSAN, 2014), ainda que há autores que defendam que na terminologia Deficiência, colocada na Declaração de Guatemala, se enquadram pessoas portadoras de transtorno mental (SANCHES e OLIVEIRA, 2011).

Vergara (2011) aponta que a legislação referente ao AEE não sinaliza o sofrimento psíquico e que a invisibilidade desses alunos, que acabam por ter atenção apenas no campo médico, gera poucos avanços para a sua inclusão. Isto é, se o aluno com sofrimento mental não "aparece", ele tampouco existe e, por isso, não há como incluí-lo. De fato, o autor evidencia que a relação que a educação tem tido com a saúde mental não é a de problematizar o sofrimento psíquico e o papel da escola, mas sim a da tentativa de normalização, corrigibilidade, docilização.

Nessa relação de inclusão/exclusão de alunos que estão em situação de sofrimento psíquico também nos parece importante, então, perguntarmos como a área da educação vem se relacionando com o campo da saúde mental e, por fim, se a escola está apta para incluir esse tipo de aluno: qual é de fato a inclusão que queremos?

Em relação ao primeiro questionamento, a Psicologia como campo profissional esteve historicamente envolvida nessa relação. O trabalho com crianças portadoras de graves transtornos mentais, de certa forma, fez que sempre houvesse parceria com o campo da educação. Por sua vez, o trabalho na área da dificuldade de aprendizagem era foco do trabalho até os anos 1970. É a partir da década de 1990 que a Psicologia se insere na perspectiva da Educação Inclusiva e passa a se interessar mais pelo tema da inclusão das pessoas portadoras de transtornos mentais nas escolas, surgindo também como dispositivo terapêutico e da própria produção de cidadania, respeito e direitos humanos (RANÑ, 2005), ainda que, na maioria das vezes, voltados para a perspectiva da criança. 
Silva (2005) considera que o trabalho da Psicologia na perspectiva inclusiva, hoje, tem também o caráter de reconhecer a ciência psicológica e seu conjunto de construções históricas pouco comprometidas com a questão dos Direitos Humanos. Ela aponta que uma das tarefas desse campo do conhecimento seja a de elucidar os lugares onde há produção de sofrimento diante dos dispositivos de institucionalização e organização feitas pelo Estado, e que produzam o mal-estar e o sofrimento das pessoas, o que podemos estender para os espaços escolares. Resta ainda para a psicologia produzir mais acerca das especificidades da inclusão educacional da pessoa em sofrimento psíquico grave, sendo que os modelos já consolidados com as pessoas com deficiência podem servir de modelo.

Em relação à inclusão que queremos, esta é uma discussão que não se esgota e que a própria construção da inclusão pode ir apontando caminhos. Mas a discussão a respeito da inclusão escolar fala sobre a possibilidade de construir novas formas de olhar o "outro", o que nos interessa significativamente no campo da saúde mental.

A questão do tratamento da diferença não é uma tarefa simples de se lidar. Como manter a igualdade e as diferenças no mesmo espaço? De fato, é um desafio, visto que há uma dificuldade em trabalhar com um discurso inclusivo, numa sociedade, por si só, excludente. A escola não se opôs a isso em sua história. A exclusão está colocada ao lado de interesses históricos e a escola se constituiu obedecendo a essa lógica. A “escola para todos" pode ser possível, mas é importante saber que diferença não é antônimo de igualdade e que, caso fosse, o diferente haveria de ser equalizado, o que não é o que queremos (NETO, 2005). Esse perigo está em, na tentativa de incluir e de olhar para o outro, mirá-lo, reconhecê-lo e mantê-lo como outro, como alguém que jamais será como "eu". Isto é, ao tentar incluir, acabamos excluindo. O desafio está em construir espaços que preservam as diferenças culturais, mas não na forma de tolerá-los, e sim, na perspectiva de que as diferenças fazem parte das tensões mundanas, com posições e significados diversos (NETO, 2005). 
Diante disso, pensamos na possibilidade de uma inclusão que, para além das diferenças, pense em sua própria constituição como forma de potencialização da vida, fortalecimento da autonomia de seus sujeitos e responsabilização sobre o mundo. Assim, recordamos, concordamos e empenhamos em trabalhar com os sujeitos a partir de uma "ética universal do ser humano", como Paulo Freire sugere. Uma ética que condena os discursos de discriminação e que considera o sujeito da possibilidade e não do determinismo. Isto é, o sujeito que é histórico, que tem a possibilidade de transformar, de tomar decisões, de romper e ser sujeito da busca e da construção. Compactuamos com a ideia de uma educação que trabalha a autonomia como processo, como vir a ser e por isso, centrada em experiências estimuladoras das tomadas de decisões e de responsabilidade, ou seja, situações que respeitem a própria liberdade (FREIRE, 2004).

É no processo de autonomia dos sujeitos, que estes, em suas tomadas de decisões e se colocando como sujeitos ativos na construção da história do mundo e de seus próprios mundos, que pensamos ser possível a construção de um mundo das diferenças, do olhar o "outro" a partir do respeito, da responsabilidade e da compreensão que todos são gente. É essa a perspectiva de inclusão com a qual acreditamos ser necessário trabalhar. Esse conceito dialoga com princípios fundamentais do modo psicossocial (COSTA-ROSA et al., 2003). Como bem assegura Freire (2004):

\footnotetext{
"Mais do que um ser no mundo, o ser humano se tornou uma presença no mundo, com o mundo e com os outros. Presença que, reconhecendo a presença como um "não-eu", se reconhece como "si própria". Presença que pensa a si mesma, que se sabe presença, que intervém, que transforma, que fala do que faz, mas também do que sonha, que constata, compara, avalia, valora, que decide, que rompe. E é no domínio da decisão, da avaliação, da liberdade, da ruptura, da opção, que se instaura a necessidade da ética e se impõe a responsabilidade" (p. 26).
} 


\section{"Alegria e muito sonho" - o relato da experiência em um CAPS II}

Como já vimos a partir das experiências de outros CAPS (AZEVEDO et al., 2014; KANTORSKI et al., 2011), a baixa escolarização dos usuários dos serviços de saúde mental é uma constatação na realidade brasileira, devido aos processos de segregação social e à dificuldade dos serviços educacionais em lidar com as diferenças, com os comportamentos que podem ser considerados desviantes e, assim, pensar a permanência estudantil e uma complexidade de situações que acabam por afastar os jovens em processo de sofrimento psíquico dos bancos escolares.

A experiência aqui relatada é fruto da vivência profissional no espaço do CAPS II, durante um ano de estágio obrigatório, da participação dos diferentes grupos terapêuticos propostos nesse espaço, da troca de conversas e da formação de vínculos com os usuários do serviço, que impôs a necessidade do olhar sobre a questão da escolarização dos usuários. Ao nos aproximarmos, conhecê-los e nos inteirarmos da história de vida desses sujeitos, é notável o fato de que muitos deles não tenham completado o ensino fundamental, e alguns ainda se mantenham analfabetos.

É a partir dessa leitura que pensamos na possibilidade de realizar um espaço de reflexão sobre a trajetória educacional e de incentivo aos usuários em reaproximar-se com esse campo, como um movimento de novas possibilidades de produção de cuidado, de articulação com novos territórios, de circulação pela cidade, de desenvolvimento de autonomia, da formação educacional, cultural e cidadã e, assim, proporcionar a reinserção social dos usuários.

O objetivo da oficina era o de ser um espaço de reflexão e incentivo à reaproximação dos usuários com o campo educacional, a partir de dinâmicas grupais, atividades reflexivas, visitas para instituições de Educação de Jovens e Adultos (EJA). O intuito também era o de incentivar a entrada dos usuários na EJA, por meio de articulações com as coordenações dos núcleos das EJAs no município. 
O grupo tinha como público-alvo usuários que estivessem em acompanhamento no CAPS II e que tivessem sido identificados pelas equipes de referências dos distritos por não terem o ensino fundamental ou médio completo, e cuja participação no grupo estivesse em conformidade com seu projeto terapêutico singular.

A proposta foi acatada pela equipe interdisciplinar do serviço e teve sua execução continuada, mesmo depois do término do estágio aqui descrito.

Iniciamos os encontros semanais, com uma hora e meia de duração, a partir de dinâmicas grupais, reflexões a partir de temas disparadores, atividades com música e leitura de textos, entre outros, com a mediação da estagiária de Psicologia. Participaram desse primeiro momento oito usuários mais fixos, embora houvesse a presença flutuante de outras pessoas. Entre os participantes, as idades variavam entre 23 e 53 anos, o que demonstra a diversidade de fatores que podem estar associados à exclusão educacional e retorno aos estudos.

No primeiro momento, os encontros foram planejados para terem atividades mais reflexivas, no sentido de identificar como foi a trajetória escolar dos usuários, se tiveram dificuldades, se há motivação para se reencontrar com os estudos e o sentido de ser estudante para cada usuário. Assim, buscou-se conhecer os usuários interessados na participação e conhecer acerca das expectativas relativas ao grupo, aos estudos e sua trajetória escolar.

Para conhecer o "sentido de estudar" foi pedido que cada um desenhasse em uma folha alguma lembrança que tinha sobre quando estudava. Alguns desenharam o local da escola, outros os lugares próximos à escola, como o mercadinho onde se reunia com os amigos. Uma usuária trouxe a escolarização como um sonho a ser realizado e outro o retrato do bullying que sofria naquele lugar. Assim, nesse primeiro momento, pudemos identificar alguns sentidos dados à escolarização: a socialização, o espaço da aprendizagem, o sonho, mas também a possibilidade de ser um espaço de produção de sofrimento. Alguns completaram até a $4^{\mathrm{a}}$ série, outros até a $5^{\text {a }}$, e poucos chegaram até a $8^{\mathrm{a}}$ série do Ensino Fundamental. 
Partiu-se, então, para a discussão do porquê voltar aos estudos e a identificação das motivações e interesses pelo tema. Para isso, foi levado um vídeo da música "Coração de estudante", e sua letra, de Milton Nascimento, para que os participantes pudessem acompanhar. Ao final do encontro, realizamos uma discussão sobre o que tratava a música e como se relacionava com o tema que estávamos trabalhando. Uma das usuárias chamou atenção para o verso da música que fala "desviaram seu destino", mas também a parte que fala a respeito de ter fé e esperança. Outra, comentou acerca do fato de que, nesse momento, para voltar aos estudos seria necessário muito amor, apoio e fé e que a música trazia isso. Discutimos acerca de ter um "espírito jovem”, um "coração de estudante", que seria buscar novos caminhos e possibilidades para a vida. Decidimos, então, dar nome ao grupo de "Coração de estudante".

A partir disso, trabalhamos "Por que estudar?". Alguns não sabiam bem o porquê, apesar de estarem motivados ao reingresso. Por sua vez, outros identificaram que o retorno aos estudos poderia lhes trazer novas oportunidades, seria uma forma de adquirir novos conhecimentos e novas alternativas de vida. Em um dos encontros, com a presença de quase todos os participantes do grupo, elaboramos um cartaz com essa mesma pergunta, para sintetizar as discussões acerca do motivo de voltar a estudar, no qual apareceram diversas justificativas: para se descobrir e ajudar aos outros, para adentrar o mercado de trabalho, para aprender mais, para ampliar as informações, para ter autonomia, porque é um direito, para conhecer novas pessoas etc. Nesse dia, debatemos a importância de o porquê saber das escolhas que fazemos, já que, quando sabemos, damos sentido às nossas escolhas e temos mais chances de alcançá -las, apesar das dificuldades que possamos encontrar no processo.

Esses motivos identificados pelo grupo dizem sobre possibilidades de pensar suas vidas, novas formas de estabelecer relações e se relacionar com o mundo, que muitas vezes se perderam em meio a outras dificuldades relacionais mais amplas. Por exemplo, grande parte dos usuários tem como espaço de socialização, além 
da família, o espaço do CAPS e os grupos que frequenta ali. Assim, induzir que a escola possa ser um espaço de novas possibilidades é dizer que há uma desconstrução na forma comum de se estar e que há motivação para habitar a cidade de forma diferente. Como coloca Dimenstein (2006), esses novos encontros com a cidade dão possibilidade entre o imprevisível da loucura e as formas institucionalizadas de estar nas ruas, instituições, bairros urbanos, de se reconstruírem. Se é na cidade e no cotidiano que estão os espaços de sociabilidade, solidariedade e convívio com o diferente, então é ela que deve ser ocupada. Isso mostra o quanto a cidade transgride a forma geográfica de ser e é reflexo das construções sociais sobre modos de viver, diferenças sociais e distribuição das riquezas. Ou seja, se a Luta Antimanicomial está para enfrentar a ideia de exclusão social, a cidade deve ser o lugar primordial de integração. Porém, impõe-se a tarefa de pensar nas condições de construção de uma cidade que seja inclusora, que não reproduza em suas divisões sociogeográficas a segregação social e, que seja passível de ocupação democrática para todas e todos.

Outro tema discutido foi o do "Direito à educação". Em um dos encontros, como havia pouca presença dos participantes, foi proposta a atividade de leitura do "Guia de Direitos Humanos: Loucura cidadã”, um guia elaborado pelo Movimento pela Saúde Mental do Estado da Bahia, para orientar usuários de saúde mental sobre seus direitos. Com a leitura do texto, pudemos discutir a respeito do que é a Reforma Psiquiátrica e a Luta Antimanicomial, e também acerca do direito que lhes é garantido sobre o estudo, considerando que o direito a estudar também fala acerca do direito de ter condições de permanecer em cuidado e de não ser forçado a abandonar os bancos escolares. Isso foi importante, pois a história da Luta Antimanicomial era desconhecida por parte dos usuários, o que lhes causou interesse. Em relação ao conteúdo a respeito do direito a estudar, discutiu-se que na questão do abandono escolar este pode se caracterizar como um problema coletivo e social, não se tratando, apenas, de uma "incapacidade individual". 
Essa experiência com os usuários trouxe à tona a consideração do lugar que a educação, e mesmo, que espaços como esses de preparação para o reingresso nas instituições educativas, possam ter na promoção de posturas críticas acerca da realidade (LUSTOSA e ROSA, 2017). Demonstra-se a importância de conhecimento sobre seus direitos e acerca da coletivização de questões que vivenciam (como o abandono escolar) para fomentar ações possíveis diante disso, como a garantia de seu direito à Educação Inclusiva. Isso vai na direção da pedagogia que propõe Paulo Freire, no sentido da conscientização de sua condição de ser para o compromisso com a práxis e o processo de libertação (FREIRE, 2015 citado por LUSTOSA e ROSA, 2017).

Procuramos, também, identificar redes de apoio para essa nova escolha. Em um dos encontros, fizemos uma dinâmica para identificar tais redes, com destaque para os vínculos familiares mais próximos, dado sua importância para os usuários. Discutimos como poderíamos contar com essa rede, em que momentos e por que seria importante ter pessoas próximas que lhe pudessem ajudar. A presença de uma nova participante nesse momento foi importante, que compartilhou sua experiência com o grupo. Tratava-se de uma usuária que havia passado pelo processo de retorno aos estudos e recém completado o Ensino Médio no modo CEJA (Ensino Médio para Jovens e Adultos no Estado de Santa Catarina), sendo que ela contou o quanto o apoio familiar lhe foi importante, em vários sentidos, no retorno à rotina, no apoio em continuar indo às aulas e na ajuda pedagógica, o que contribuiu muito para a discussão do grupo. Em um segundo momento dessa atividade sobre a rede de apoio, identificamos qual era a escolarização e o trabalho das pessoas cujo vínculo significativo fora identificado. Alguns dos familiares e amigos completaram o ensino médio, mas a maioria não, e muitos trabalhavam na área de serviços gerais, que não exige grau elevado de escolarização. No debate com o grupo, trabalhamos a respeito de como as referências familiares operam nas suas vidas e uma usuária trouxe a importância do trabalho com 
sentido, independentemente da escolarização, a partir do exemplo de um familiar.

Sanches e Oliveira (2011) falam sobre como, no processo de reinserção social de indivíduos com transtorno mental, o envolvimento e o comprometimento da família e da rede de apoio que os sujeitos possuem são importantes, já que esta continua representando a garantia da sobrevivência e proteção de seus membros. Podemos considerar que essa proteção seja para além do auxílio material, mas, como os próprios usuários deram como exemplo, pessoas que possam "incentivar a ir às aulas", "acordar nos dias de chuva", "incentivar que se continue a estudar". Nesse sentido, na escola que se propõe a pensar a inclusão de seus alunos não pode ser mais possível trabalhar com o distanciamento entre família e escola (SANCHES e OLIVEIRA, 2011). É importante ter em conta a questão da rede de apoio ampliada, para além dos vínculos familiares, nessa contribuição de cuidado. São muitos os casos de usuários que possuem vínculos familiares rompidos ou com dificuldades e a identificação de uma rede de apoio mais ampla e o próprio grupo pode abrir possibilidades de vínculos para fortalecer o processo de retorno à educação.

As dificuldades que seriam encontradas no reingresso também foram tema de debates em outros encontros. A partir da escuta da música "Estudo errado", de Gabriel Pensador, problematizamos a função da escola, como ela tem se dado e as condições das escolas públicas brasileiras. A partir dessa atividade, listamos as possíveis dificuldades que poderiam ser encontradas no reingresso. Algumas delas são: dificuldade de retorno à rotina, a presença da vergonha pelas dificuldades enfrentadas e o desafio da participação, dificuldade na aprendizagem das matérias, as avaliações e cobranças, alguns efeitos dos medicamentos como o sono, vigília ou esquecimento, entre outras. $\mathrm{O}$ próximo encontro seria então o de retomada dessas dificuldades para a identificação de possíveis estratégias.

Essas dificuldades identificadas pelos usuários participantes do grupo vão ao encontro do que Camargo (2015) encontrou em 
seu estudo na EJA. Ele relata que frequentar a escola na idade adulta pode acarretar sentimentos de incompetência, dificuldade com conteúdos programáticos, como é o caso da matemática, alguns conflitos familiares (já que alguns papéis na organização familiar mudam), desconforto pela falta de familiaridade com a cultura escolar e outros. Nesse sentido, reafirma-se a importância do grupo para que se pensem as estratégias de enfrentamento dessas questões, mesmo anteriormente ao ingresso às instituições escolares.

Se, por um lado, trabalhamos com os usuários, seus desejos e a preparação para o reingresso ao espaço escolar, por outro, também, buscamos a aproximação com o próprio campo escolar que iria recebê-los. Assim, procuramos uma articulação intersetorial com as coordenações de EJAS da cidade, a fim de firmar parcerias para que fosse possível, para além do encaminhamento comum de novos estudantes, um processo acompanhado da entrada desses usuários com características singulares. Isto é, discutiu-se a importância de o CAPS e a EJA estarem em comunicação permanente. Dessa forma, foi aberto o canal para a partilha de informações e também o de formação dos professores dos diferentes núcleos de EJA.

Destacamos, dessa forma, as ações intersetoriais dentro dos CAPS. Os próprios cadernos de orientação dos CAPS (Ministério da Saúde, 2004) trazem sobre o papel estratégico do serviço em articular e tecer redes cumprindo o caráter comunitário e territorial de atenção à saúde integral dos sujeitos. Assim, os CAPS teriam a função de suporte direto na rede de saúde, junto às equipes de saúde da família, assim como, na articulação de recursos de outras redes: sociossanitárias, jurídicas, escolares e outras.

Esse movimento de criação de rede e articulação também seria importante a partir das próprias instituições escolares. Apesar de haver documentos que falem sobre a importância da intersetorialidade na relação saúde mental e educação (SANCHES e OLIVEIRA, 2011), as resistências e dificuldades por parte dos serviços ainda se fazem presentes. Sendo assim, essa articulação poderia ser um passo na direção de possibilitar um processo de desenvolvimen- 
to significativo de aprendizagem, de minimização de sua condição de sofrimento, melhorar o vínculo com as famílias e, de fato, garantir o direito à educação.

\section{"Há que se cuidar do mundo"}

\section{Considerações finais}

Os caminhos que buscamos transitar neste trabalho falaram a respeito das diferentes lógicas de cuidado que estão em tensionamentos no cenário atual na Saúde Mental. Nessa direção, se destacam os desafios do modo psicossocial buscar a criação de lógicas de cuidado integral, que coloquem como foco o sujeito e seu modo de estar no mundo, em oposição a uma lógica segregatória, que retira do sujeito a sua potência de vida. No campo escolar, os tensionamentos também se impõem e refletem racionalidades semelhantes ao campo da saúde mental: aqueles modelos que colocam a escola como ferramenta de manutenção do status social estabelecido, excluindo os diferentes e neutralizando as diferenças. Nessa direção, se discute a ocorrência de uma violência simbólica, ou seja, a imposição arbitrária do sistema simbólico da cultura dominante sobre os sujeitos, os quais, uma vez que não estejam muito bem ajustados ao sistema, acabam sofrendo mais fortemente processos de exclusão educacional (BOURDIEU, PASSERON, 1992). Nesse caso, se reforçam processos de exclusão social já vivenciados por pessoas em processo de sofrimento psíquico, assim como, naturalizam-se suas vulnerabilidades psicossociais.

Por sua vez, temos as propostas de escolas inclusivas, promotoras de saúde e mediadoras da autonomia e cidadania das pessoas, conforme projeto pedagógico de boa parte das EJAs e dos processos educacionais que se pautam na pedagogia freiriana. Como vimos, nos diferentes setores em questão, há conquistas substanciais na construção de uma lógica de cuidado e de educação que acolha as diferenças e que reconheça os direitos das pessoas com características especiais, como o sofrimento psíquico. 
Sendo assim, o modo psicossocial consolidado a partir da Reforma Psiquiátrica e a escola inclusiva e promotora da saúde, postulada a partir da LDB, de 1996, estão ainda em construção de suas estratégias, sendo desafiados na criatividade e eficácia de suas ações. Trata-se de um processo de construção histórico-estrutural, em processo de consolidação de suas ferramentas e produção de formas diferentes de cuidado e de educação, pautadas na autonomia e na liberdade (SANCHES e OLIVEIRA, 2011).

Nessa direção, a oficina "Coração de Estudante" buscou se inserir, contribuindo como diálogo intersetorial entre saúde e educação, ao visar o cuidado integral das pessoas com sofrimento psíquico grave e a garantia do direito à educação. Surgiu por meio do reconhecimento de que muitos dos usuários do serviço tiveram o direito ao estudo violado, repercutindo no abandono escolar e no reforço de seu processo de vulnerabilização psicossocial e produção da loucura.

Somos desafiados a refletir a respeito de nossos próprios preconceitos enquanto profissionais, sobre a forma como estamos "olhando o outro" (NETO, 2005) e como estamos tentando incluir o outro. Assim, na direção de Paulo Freire (2005), o processo de consolidação da autonomia do usuário, centrado na liberdade a partir da tomada de decisões, e na responsabilidade diante do olhar sobre o mundo, põe-se como um desafio técnico.

Porém, muitas das conquistas aqui referidas estão novamente sob ameaça. Ora, o que está em jogo, então? Está o tensionamento das lógicas de cuidado e de educação, pois as formas conservadoras e ainda hegemônicas de ser e estar, com base na normatização dos corpos e desejos, no cerceamento da liberdade de ser, nas exigências de adequação ao status quo, ainda seguem vigentes e, neste momento político do Brasil, desde 2016, passaram a reger as políticas públicas, colocando em ameaça a lógica pautada no respeito à cidadania e aos direitos humanos.

Assim, o trabalho da saúde mental e o da educação se caracterizam pela batalha diária contra uma sociedade individualista, 
excludente e voltada para os interesses do pensamento hegemônico. Ou seja, trabalhamos com a questão social, que aparece na reprodução do ciclo de sofrimento psíquico, do abandono dos sujeitos nessa situação, na violação de seus direitos, na impossibilidade social de permanência de certos jovens em situação de vulnerabilidade na escola regular.

Destacamos que há aparatos legais insuficientes para a inclusão de pessoas em situação de sofrimento mental. A superação desse atraso passa pela construção, no trabalho da rede de Atenção Psicossocial, de mecanismos intersetoriais que garantam o processo de permanência nas instituições escolares. Essa é somente uma das frentes de atuação, mas que pode atingir de forma mais ampla outros sujeitos.

Ressaltamos a experiência de estágio em processos clínicos no CAPS como espaço de potencialização da formação acadêmica em Psicologia. Nesse sentido, se coloca a importância da formação de psicólogos na saúde pública que coloquem em questão o comprometimento social da profissão e que produzam também uma posição ética dos profissionais em formação sobre as formas de discriminação, de exclusão social e de normatização dos corpos. Nesse sentido, evidencia-se que o estágio profissionalizante em saúde pública nos coloca diante dos desafios de criar essas novas formas de cuidado na lógica psicossocial e de estar dentro do tensionamento que é a construção da Reforma Psiquiátrica diariamente para, assim, construir uma Psicologia e uma Educação latino-americana potente e produtora de vida.

Por consequência, produzir transformações passa por resgatar a intencionalidade do sujeito em situação de sofrimento mental para mediar sua condição de intervir, transformar, avaliar, decidir, romper com as amarras de uma sociedade que excluiu o diferente, assim como expressa Dimenstein (2006, p. 79), de "ir em busca de milagres em favor do inesperado e do imprevisível que só podem nos tocar se sentirmos o hálito do mundo em nossa pele". Portanto, se faz necessário, cada vez mais, imaginar novas perspectivas, reforçar a 
interlocução saúde-educação, renovar a esperança, ter juventude, ter fé, alegria e muito sonho, isto é, ter "coração de estudante".

\section{Referências}

AMARANTE, Paulo. O homem e a serpente: outras histórias para a loucura e a psiquiatria. Rio de Janeiro: Editora Fiocruz, 1996.

ARBEX, Daniela. Holocausto Brasileiro. São Paulo: Geração Editorial, 2013.

AZEVEDO, E. B. et al. Alfabetização para pessoas portadoras de transtorno mental em um Centro de Atenção Psicossocial. Revista da Universidade Vale do Rio Verde, v. 12, n. 1, 2014 [p. 739-747]. Recuperado de:

$<\underline{\text { http://periodicos.unincor.br/index.php/revistaunincor/article/view/1428/ }}$ pdf $158>$

BASAGLIA, F. Prefácio. In: Amarante, P. O homem e a serpente: outras histórias para a loucura e a psiquiatria. Rio de Janeiro: Fiocruz, 1996.

BOCCARDI, D. O. Os caminhos da saúde mental e Gestalt-terapia: compreensão de campo na atenção psicossocial. In: Belmino, M. C. Gestalt Terapia e atenção psicossocial (p. 60-107). Fortaleza: Premius, 2015.

BOURDIEU, P.; PASSERON, J. A Reprodução: elementos para uma teoria do sistema de ensino, 3. ed. Rio de Janeiro: Francisco Alves, 1992.

BRASIL. Ministério da Educação. Lei de Diretrizes e Bases da Educação Nacional. LDBEN 9394, de 1996. Brasília: Ministério da Educação, 1996.

BRASIL. Congresso Nacional. Lei 10.216. Brasília, 2001.

BRASIL. Ministério da Saúde. Saúde Mental no SUS: Os Centros de Atenção Psicossocial. Brasília: Ministério da Saúde, 2004.

BRASIL. Ministério da Saúde. Nota Técnica No. 11/2019-CGMAD/DAPES/ SAS/MS. Esclarecimentos sobre as mudanças na Política Nacional de Saúde Mental e nas Diretrizes da Política Nacional sobre Drogas, 2019.

CAMARGO, J. S. A educação de adultos na Educação de Jovens e Adultos como promotora da saúde mental. Saúde e Pesquisa, v. 8, Edição Especial, p. 31-44, 2015. 
CORREIA, L. C. (Org.). Guia de direitos humanos loucura cidadã. Salvador: AMEA.

COSTA, Ileno Izídio; BRAGA, Filipe Willadino. Clínica sensível à cultura popular na atenção ao sofrimento psíquico grave. Fractal, Rev. Psicol, v. 25, n. 3, p. $547-$ 562, set./dez. 2013.

COSTA-ROSA, A., LUZIO, C. A., \& YASUI, S. Atenção Psicossocial: rumo a um novo paradigma na Saúde Mental Coletiva. In: SCLIAR, M. et al. (2003). Archivos de Saúde Mental e Atenção Psicossocial. Rio de Janeiro: Nau Editora.

DELGADO, P. G. Reforma psiquiátrica: estratégias para resistir ao desmonte. Trabalho, Educação e Saúde, 17 (2), mai. 6, 2019. http://sci-hub.tw/10.1590/19817746-sol00212

DIMENSTEIN, M. O desafio da política de saúde mental: a (re)inserção social dos portadores de transtornos mentais. Mental, ano IV, n. 6, 2006 [p. 69-83]. ISSN 1679-4427

ESTANISLAU, G. M. e BRESSAN, R. A. (Org.). Saúde Mental na escola: o que os educadores devem saber. Porto Alegre: Artmed, 2014.

FREIRE, P. Pedagogia da Autonomia. Rio de Janeiro: Paz e Terra, 2004.

KANTORSKI, L. P. et al. A importância das atividades de suporte terapêutico para o cuidado em um Centro de Atenção. Rev. Enferm. Saúde, v. 1, n. 1, 2011 [p. 4-13]. Recuperado de: https://www.periodicos.ufpel.edu.br/ojs2/index.php/ enfermagem/article/view/3401/2792

LUSTOSA, A. F. M. e ROSA, L. C. S. Desigualdade Social e as expressões da questão social na saúde mental. In: TEIXEIRA, S. M. e MACEDO, J. P. S. (Org.). Políticas Sociais na Contemporaneidade: programas, serviços e trabalho profissional (p. <41-61>), Teresina: Edufpi, 2017.

MACHADO, M. F. A. S.; MONTEIRO, E. M. L. M.; QUEIROZ, D. T.; VIEIRA, N. F. C.; BARROSO, M. G. T. Integralidade, formação de saúde, educação em saúde e as propostas do SUS - uma revisão conceitual. Ciência\& Saúde Coletiva, 12 (2): 335-342, 2007.

NETO, A. V. Quando a inclusão pode ser uma forma de exclusão. In: MACHADO, A. M. et al. Psicologia e direitos humanos: educação inclusiva, direitos humanos na escola. (p. <55-71>). São Paulo: Casa do Psicólogo, 2005. 
RANÑA, W. Direitos humanos, educação inclusiva e reforma psiquiátrica para a criança e o adolescente. In: MACHADO, A. M. et al. Psicologia e direitos humanos: educação inclusiva, direitos humanos na escola (p. <83-99>). São Paulo: Casa do Psicólogo, 2005.

SANCHES, A. C. G. e OLIVEIRA, M. A. F. Educação inclusiva e alunos com transtorno mental: Um desafio interdisciplinar. Psicologia: Teoria e Pesquisa, v. 27, n. 4, 2011 [p. 411-418]. Recuperado de: < http://www.scielo.br/pdf/ptp/ v27n4/04.pdf $>$

SILVA, M. V. O. A psicologia, os psicólogos e a luta pelos direitos humanos: da reflexão à ação. In: MACHADO, A. M. et al. Psicologia e direitos humanos: educação inclusiva, direitos hum.anos na escola (p. <13-39>). São Paulo: Casa do Psicólogo, 2005.

VASCONCELOS, E. M. (coord.). Manual dos direitos e deveres dos usuários e familiares em saúde mental e drogas. Rio de Janeiro: Escola do Serviço Social da UFRJ, Brasília: Ministério da Saúde, Fundo Nacional de Saúde, 2014.

VERGARA, E. M. A in/visibilidade do sofrimento psíquico nas bio/políticas de educação inclusiva e saúde mental (tese de doutorado). São Leopoldo, 2011. Recuperado de: <http://www.repositorio.jesuita.org.br/bitstream/handle/ UNISINOS $/ 3580 /$ invisibilidade_sofrimento.pdf? sequence $=1$ \&isAllowed $=_{\mathrm{y}}>$

\section{Luna Cassel Trott}

ORCID iD http://orcid.org/0000-0002-0489-2240

Universidade Federal do Rio Grande do Sul

Graduada em Psicologia pela Universidade Federal de Santa Catarina. Residente em Saúde Mental Coletiva pela Universidade Federal do Rio Grande do Sul

Daniela Ribeiro SchNeIder

ORCID iD http://orcid.org/0000-0002-2936-6503

Universidade Federal de Santa Catarina

Mestrado em Educação pela Universidade Federal de Santa Catarina (1993). Doutorado em Psicologia (Psicologia Clínica) pela Pontifícia Universidade Católica de São Paulo, Brasil(2002). Pós-Doutorado em Ciência da Prevencao ena Universidad de Valencia(2012) e University of Miami(2019). Prof. Titular da Universidade Federal de Santa Catarina, Brasil

Submetido em: 30-9-2019

Aceito em: 17-11-2019 